\title{
Waarderingswoord aan kollegas B. Spoelstra en V.E. d'Assonville
}

A le R. du Plooy

Rektor

Teologiese Skool Potchefstroom

\section{Inleiding}

Twee van ons kollegas by die Teologiese Skool, naamlik B. Spoelstra en V.E. d'Assonville het reeds die ouderdom van 65 jaar bereik. Wameer professore hierdie leeftyd bereik, word daar gewoonlik in terme van sinodebesluite oor emeritering besin. Dit is in elk geval 'n tydstip waarop daar teruggekyk kan word na 'n lang tydperk van diens in die kerke.

Prof Bouke Spoelstra kon in hierdie jaar sy veertigjarige dienstyd as bedienaar van die Woord en as professor aan die Teologiese Skole te Hammanskraal en te Potchefstroom met dankbaarheid gedenk. Hoewel hy reeds die ouderdom van 65 jaar bereik het, het die Kuratorium op sy versoek sy dienstyd verleng sodat hy nog in die diens as professor werksaam is.

Ons beskou dit nou as 'n geskikte geleentheid om ons opregte waardering in hierdie uitgawe van In die Skriflgg aan hom te betoon.

In die geval van prof. Victor d'Assonville was dit hom nie beskore om normaalweg uit die diens as professor aan die Teologiese Skool te emeriteer nie, en tog het hy oor 'n tydperk van byna 40 jaar as bedienaar van die Woord en as professor kostelike werk gedoen waarvoor ons hom wil huldig en dank betoon.

Dit is 'n spontane behoefte by ons as kollegas om erkenning te gee aan die werk van hierdie twee broeders in die kerk van Jesus Christus, en om in kort waarderingswoord tot hulle te rig. Paulus leer ons in 1 Tessalonisense 5: 12-13: "Erken die mense wat so hard onder julle werk ... Betoon in liefde die hoogste agting aan hulle ter wille van hulle werk."

Ek het met dic hulp van die moderne rekenaartegnologie vasgestel watter bydrae hulle in die vorm van publikasies, artikels en geskrifte gelewer het. Hoewel die uitslag nie 'n verrassing is nie, is dit inderdaad indrukwekkend en verstommend om te sien wat die volume en gehalte van hul werk is. Dit is nie moontlik om in hierdie oorsigtelike huldeblyk werklik 'n volledige weergawe te gee van hulle 
bydrae in die teologie en kerklike lewe nie. Nogtans wil ek probeer om aan u 'n globale beeld en algemene indruk van die lewe en werk van hierdie twee begaafde broeders te gee.

\section{Beknopte curriculum vitae van B. Spoelstra}

Bouke Spoelstra is op 2 Januarie 1927 as die oudste seun van ds. en mev. T.T. Spoelstra in Johannesburg gebore. Hy is op 8 April 1953 met Chris van Wyk getroud, en uit die huwelik is vier seuns gebore.

\section{Studies}

Hy matrikuleer in 1943 aan die Hoërskool Gimnasium in Potchefstroom. Daama begin hy sy tersiêre studies aan die PU vir CHO met die oog op die opleiding as predikant. In 1946 behaal hy die B.A.-graad (met lof), in 1947 die B.A. Hons (met lof) en in 1950 die M.A.-graad (met lof).

Hy voltooi sy teologiese en kandidaatsopleiding aan die Teologiese Skool Potchefstroom en in 1952 verwerf hy die graad Th.B (met lof). Hiermee het hy egter nie aan die einde van sy teologiese en akademiese studies gekom nie, want terwyl hy bedienaar van die Woord was, voltooi hy sy D. Litt. in 1963 en behaal ook later in 1965 die Th.M.

In sy studentedae was hy besonder aktief in die studentelewe en dien onder meer as voorsitter van die Studenteraad van die $\mathrm{PU}$ vir $\mathrm{CHO}$.

\section{Predikant}

Nadat hy aan die einde van 1952 tot die bediening van die Woord toegelaat is, dien hy in verskillende kerke:

- Die Gereformeerde Kerk Middelburg (Kaap): 1953-1957;

- Die Gereformeerde Kerk Bellville: 1957-1964;

- Die Gereformeerde Kerk Waterkloofrand: 1964-1970.

\section{Professor}

In 1970 word hy deur die Gereformeerde Kerke in Suid-Afrika as professor beroep en bevestig. Tot aan die einde van 1988 dien hy in hierdie hoedanigheid by die Hammanskraalse Teologiese Skool met hoofopdrag die dosering van die ekklesiologiese vakke. By meer as een geleentheid word hy as rektor van die Hammanskraalse Teologiese Skool aangewys. 


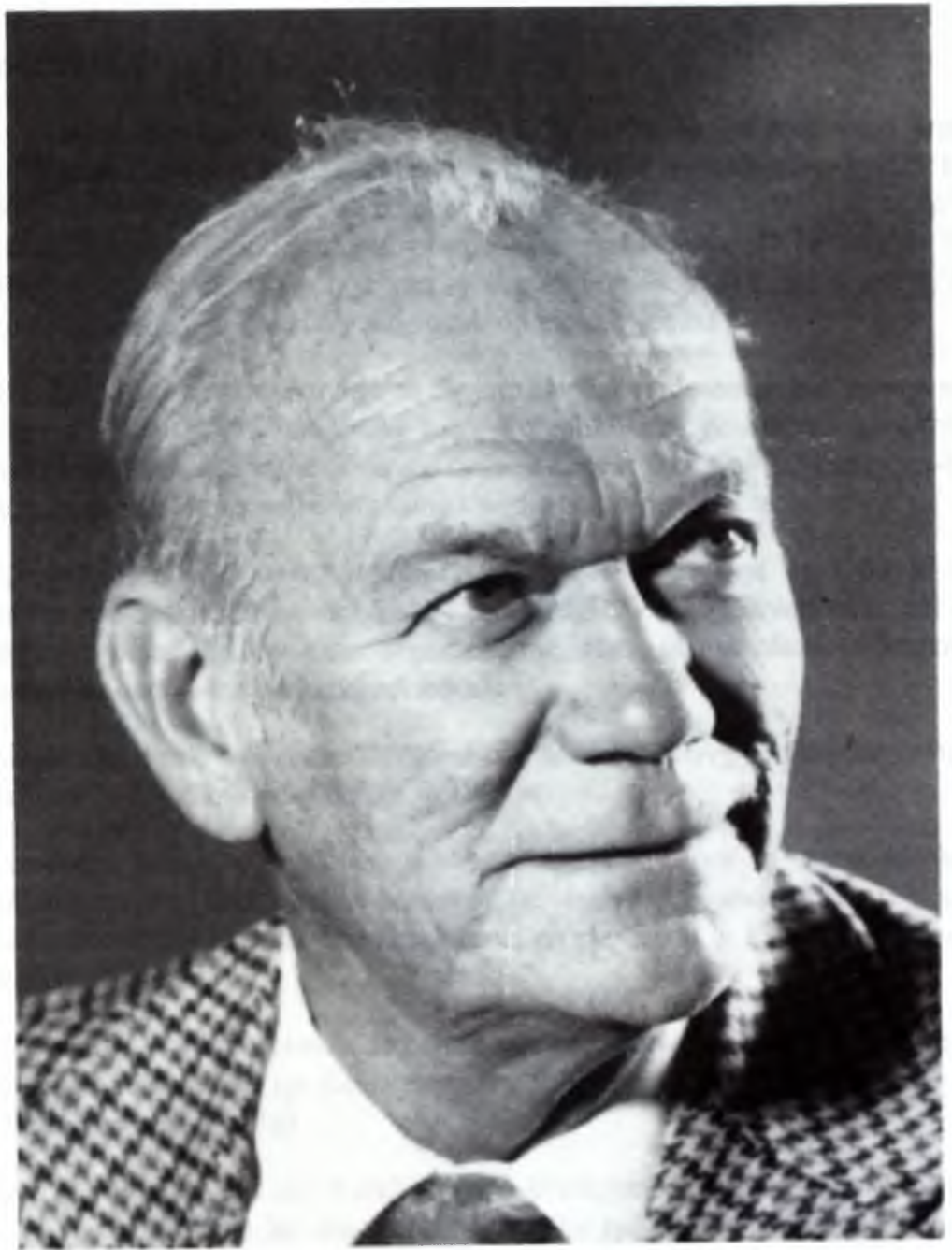

Bouke Spoelstra 
Sedert 1989 dien hy as professor aan die PU vir CHO en die Teologiese Skool Potchefstroom - nou met die opdrag om die diakoniologiese vakke te doseer.

\section{Akademikus}

In sy akademiese loopbaan presteer Bouke Spoelstra op buitengewone wyse. Met die gawes van hart en verstand en met die vermoê om deurgaans hard te kan werk lewer hy in die teologie 'n kostehke bydrae. Sy eintlike belangstelling lê op die terrein van die ekklesiologie oftewel kerkgeskiedenis en kerkreg. Tog verdiep hy hom in die latere fase van sy akademiese loopbaan indringend in die diakoniologie en doen grondliggende werk op hierdie gebied.

Hy het die goeie eienskap om deur al die jare student en dosent te bly, en van verstarring is daar by hom nie sprake nie. Sy publikasies getuig van oorspronklikheid, van 'n besondere liefde vir die Gerefonneerde leer, van 'n akademies-kritiese gees en van 'n positiewe uitbouing van die gereformeerde teologie.

Sy proefskrif, Die Doppers in Suld-Afrika 1760-1899, wat in 1963 in die Departement Geskiedenis onder leiding van prof. D.W. Knuger voltōoi is, het nie alleen wye belangstelling gaande gemaak nie, maar is inderdaad ' $n$ besonder waardevolle bydrae tot die kerkgeskiedenis.

'n Ander magistrale werk van B. Spoelstra, getitel Kerkreg en kerkregermg Handboek by die Kerkorde verskyn in 1989.

In verskeie boeke of bydraes in boeke skryf hy oor 'n verskeidenheid kerkhistoriese en kerkregtelike onderwerpe. Hy is 'n mede-outeur van 'n skoolhandboek oor die vak kerkgeskiedenis en skryf ook 'n katkisasiehandboek vir kerkgeskiedenis.

Bouke verrig baanbrekerswerk ten einde die teologiese tydskrif In die Skrifig saam met ander teoloë op die been te bring, en hy is van 1970 tot 1986 die hoofredakteur van dié blad.

Sedert die stigting van die Kerkhistoriese Werkgemeenskap in Suid-Afrika in 1970 is hy 'n aktiewe lid daarvan en lewer hy tydens die kongresse dikwels referate. Hy is ook lid van die Werkgemeenskap vir Praktiese Teologie.

Hy het hoe langer hoe meer in sy geskrifte en artikels laat blyk dat hy 'n intensiewe belangstelling en waardering vir die werk van Calvyn het. Op die Calvyn-kongresse het hy dikwels insiggewende referate gelewer, en hom in sy eie denke veral deur Calvyn laat lei.

Die naam Bouke Spoelstra verwerf egter veral onder teoloe bekendheid deurdat hy deurlopend wetenskaplike artikels in teologiese tydskrifte publiseer. Die 
meeste artikels verskyn in In die Skriflig, hoewel hy ook in ander bimelandse en buitelandse teologiese tydskrifte publiseer. Die inhoud van sy geskrifte laat duidelik blyk dat hy 'n besondere liefde vir nadenke oor die kerk het, en dat hy deurgaans aan die reformatoriese visie op die kerk vashou.

\section{Kerklike terrein}

Op kerklike terrein is hy besonder aktief, en daar word gereeld van sy bekwame diens en besondere insigte en adviese gebruik gemaak. By meer as een geleentheid is hy na die Gereformeerde Ekumeniese Sinode afgevaardig en is hy lid van verskillende deputate van die Algemene en Nasionale Sinodes. Hy dien verskeie kere op die moderamen van Nasionale Sinodes.

Wanneer die Handelinge van die Nasionale Sinodes nagegaan word, is dit duidelik watter prominente plek hy in die kerklike gemeenskap van die Gereformeerde Kerke in Suid-Afrika inneem. Ek dink in besonder aan sy bydrae in die studies oor die amp van die diaken, oor die argief, oor die kerkorde, oor die eenheid van die kerk, oor die struktuur van die kerke - om slegs enkeles te noem. Bouke Spoelstra is iemand aan wie die Gereforneerde Kerke in Suid-Afrika groot dank verskuldig is omdat hy voortdurend die kerke op die Gereformeerde spoor van kerkregering gelei het - soms selfs ten koste van homself.

In die breë kerklike lewe het hy die eeufeesgedenkboeke van die Gereformeerde Kerke Colesberg en Venterstad geskryf, en is hy tans besig om as medewerker die geskiedenis van die sending in die Gereformeerde Kerke in Suid-Afrika te beskryf. Sy skriftelike en mondelingse adviese by mindere en meerdere vergaderinge, aan kerkrade en individue word besonderlik gerespekteer en waardeer.

\section{Algemeen}

In die publieke lewe het hy bekendheid verkry deur sy sesweeklikse rubriek in Beeld. ' $n$ Kenmerk van hierdie artikels is dat dit aktueel en insiggewend is, maar veral getuig van sy uitstekende historiese perspektiewe.

Hy is voorwaar ' $n$ begenadigde dienskneg van die Here wat tot groot seën en welsyn aan ons as kerk van Jesus Christus gegee is.

Weens sy kritiese en intellektuele vermoëns, sy eiesoortige individualistiese en selfstandige denke het hy soms reaksie ontlok, maar hierdeur stimuleer hy sy kollegas, die studente en ook die kerke steeds tot deeglike verantwoording en gesonde reformasie. 
In Chris, sy eggenote, het die Here aan hom 'n vrou gegee wat by hom pas en in alles kan bystaan. As gesin - saam met hulle kinders en famihe - is hulle ' $n$ voorbeeld vir die kudde van die Here. Hulle is gemaklike mense, boeremense. Hulle het 'n opregte liefde vir God en sy kerk, en 'n warm gevoel vir ons land en volk.

Nou dat hy die ouderdom van 66 jaar bereik het, en nog steeds aktief in die teologiese en kerklike lewe kan wees, is ons die Here dankbaar vir die besondere kragte en gesondheid wat hy ontvang.

Ons wil hom en sy vrou met hulle gesin aan die genade van die Here opdra, en die hoop uitspreek dat solank dit die Here mag behaag, Hy hom steeds tot seën en opbou van sy kerk sal gebruik.

Ons verseker hom van ons hoogste waardering en dankbaarheid.

Sy diens in die koninkryk en kerk van Jesus Christus, en in besonder in die gemeenskap van die Gereformeerde Kerke in Suid-Afrika het nie en sal nie ongemerk verbygaan nie. Dit dien eerder vir ons as 'n bron van inspirasie en besieling.

\section{Beknopte curriculum vitae van V.E. d'Assonville}

Victor Edouard d'Assonville is op 18 Augustus 1927 op 'n plaas in die Vrystaat gebore. Vandag is die plek 'n eiland in die Vaaldam.

Hy is met Johanna Mathilde Therése van der Merwe getroud, en uit die huwelik is vyf kinders gebore, twee seuns en drie dogters.

\section{Studies}

In 1945 matrikuleer hy aan die Hoërskool Ventersdorp. Sy tersiêre onderrig ontvang hy aan die PU vir CHO. Hy behaal die B.A.-graad in 1950 en die Th.B iII 1954.

Tydens sy studentejare aan die $\mathrm{PU}$ vir $\mathrm{CHO}$ tree hy as studenteleier na vore. In 1952 is hy voorsitter van die Studenteraad, en in dieselfde jaar verwerf hy die Abe Bailey-reisbeurs. Hy ontvang ook van die PU vir $\mathrm{CHO}$ die Raadsmedalje vir voortreflike diens.

Aan die PU vir CHO verwerf hy in 1971 die Th.M (met lof). In 1972 lê hy aan die PU vir CHO die vakke Kerkgeskiedenis en Kerkreg af met die oog op sy doktorale studies. 
Dit is interessant dat hy toe reeds in die besit van 'n Ph.D-graad was wat hy in 1968 aan die Universiteit van Natal verwerf het. Met die oog daarop het hy in 1958-1959 in Edinburgh, Skotland navorsing oor die sestiende-eeuse Reformasie gedoen waarin hy in besonder op John Knox toegespits het. In Edinburgh voltooi hy die eerste deel van die doktorale studies, en later die tweede deel aan die Universiteit van Natal. Die titel van die proefskrif is John Knox and the Institutes of Calvin. Die werk ontlok groot belangstelling in die buiteland, veral in die Engelssprekende Calvinistiese wêreld.

\section{Bedienaar van die Woord}

Victor d'Assonville se eerste gemeente waarin hy as bedienaar van die Woord bevestig word, is die Gerefonneerde kerk Pietermaritzburg waar hy van 1954 tot 1961 dien.

Daarna bedien hy die volgende Gerefonneerde Kerke:

- Johannesburg-Sentraal: 1961-1965;

- Pretoria-Sunnyside: 1965-1970;

- Potchefstroom-Noord: 1970-1971,

- Cachet: 1971-1974,

- Noordbrug: 1974-1978.

In 1979 word hy professor aan die Teologiese Skool Potchefstroom. Sy hoofopdrag is die dosering van Kerkgeskiedenis en Dogmageskiedenis. Hy is ook deur die PU vir $\mathrm{CHO}$ as professor benoem met die oog op die dosering van dieselfde vakke in die Fakulteit Teologie.

\section{Akademikus}

Op akademiese gebied onderskei hy hom as ' $n$ ywerige teoloog. Elkeen wat die geskrifte van Victor d'Assonville ter hand neem, bemerk dadelik dat hy 'n gawe het om gemaklik en vloeiend te skryf. Daar verskyn inderdaad 'n groot aantal publikasies in die vorm van veral boeke, tydskrifartikels en populêre artikels uit sy pen

Die ruimte ontbreek om volledige besonderhede hiervan te gee, maar dit is meer as die moeite werd om met behulp van die moderne rekenaartegnologie by die Ferdinand Postma-biblioteek daarvan kennis te neem. Ek volstaan met enkele opmerkings en verwysings in hierdie verband. 


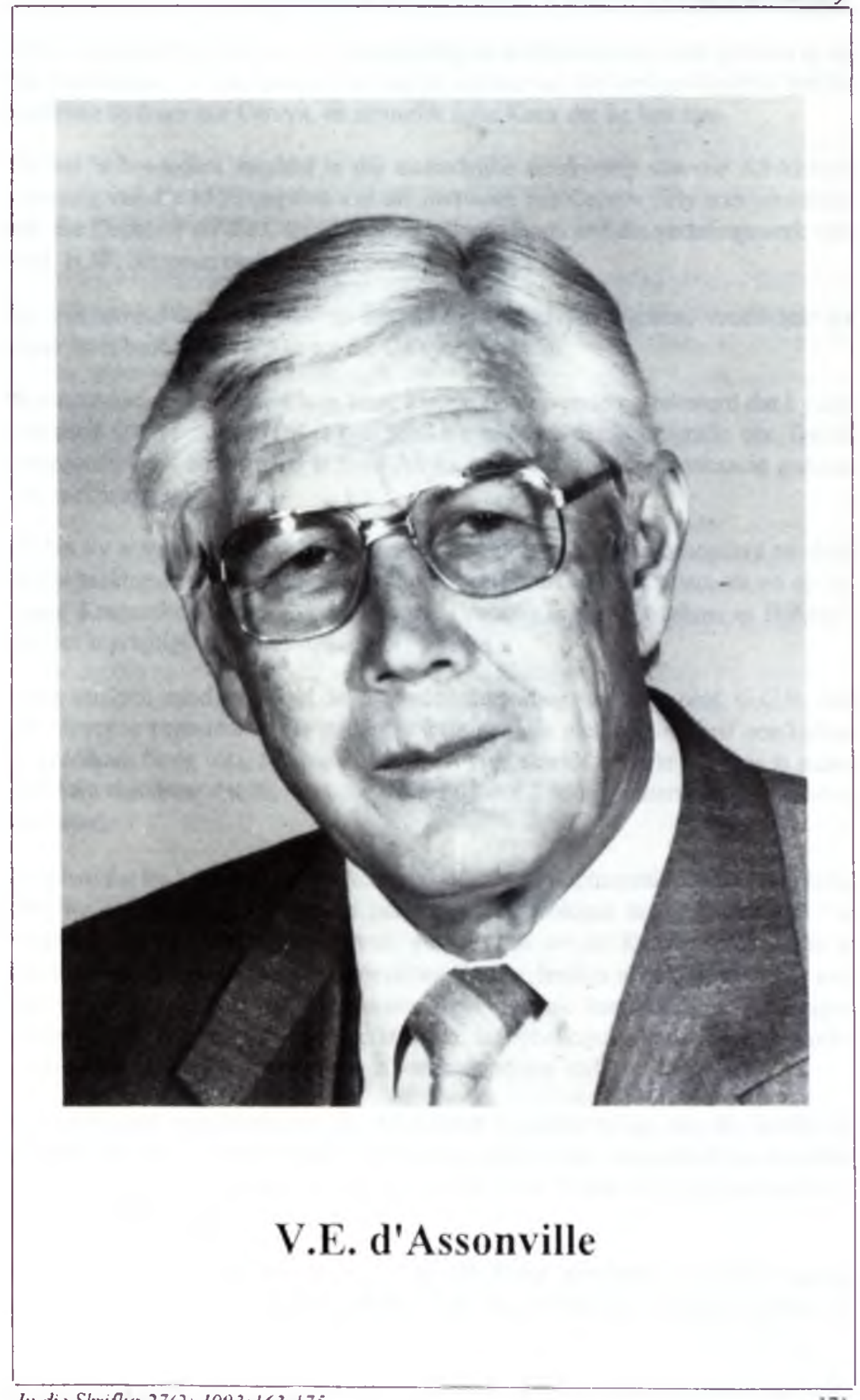


Uit sy geskrifte blyk dit dat sy belangstelling as kerkhistorikus veral gefokus is op die Reformasie, en ten opsigte van hierdie terrein van die kerkgeskiedenis het hy kostelike bydraes oor Calvyn, en natuurlik John Knox die lig laat sien.

Hy het ' $n$ besondere aandeel in die uiteindelike verskyning van die Afrikaanse vertaling van die 1559-uitgawe van die Institusie van Calvyn. Hy was voorsitter van die Deputate vir die Calvyn Jubileum Boekefonds wat die vertalingswerk van prof. H.W. Simpson onder meer moontlik gemaak het.

By geleentheid lewer hy self op internasionale Calvynkongresse voordragte en maak so 'n besondere bydrae tot die Calvynnavorsing.

Wanneer ons nader aan eie huis kom, kan dit onomwonde gestel word dat hy dié outoriteit oor Totius is. Dit is ons gelukkig beskore dat ' $n$ biografie oor Totius waaroor hy lank en intensief in Suid-Afrika en in die buiteland navorsing gedoen het, eersdaags sal verskyn.

Hy het by al sy akademiese belangstelling in Totius ook nog 'n besondere aandeel in die praktiese inrigting van die wonings van Totius in Potchefstroem en op sy plasie Krugerskraal buite Potchefstroom. Vandag is die Totiushuis in Potchefstroom 'n pragtige en besienswaardige museum.

Dit is miskien minder bekend dat hy onder die leiding van wyle prof. G.C.P. van der Vyver as promotor in die middel sewentiger jare met 'n proefskrif oor Totius as predikant besig was, toe prof. Van der Vyver skielik oorlede is. Ons is saam met hom dankbaar dat die kosbare navorsing oor Totius op hierdie wyse voltooi kan word.

Behalwe dat hy hom primêr met kerkgeskiedenis en dognageskiedenis besig hou, dien hy ook met toewyding die gereformeerde teologie in die algemeen. 'n Redelike resente publikasie van hom, getitel (iids vir die Kerkgeskiedenis, is 'n handige bron vir studente en 'n samevatting van sy lesings in kerkgeskiedenis aan die Teologiese Skool. Hierbenewens skryf hy ook handboeke in Dogmageskiedenis, en veral met die oog op studente in Bybelkunde, handboeke in Kerkgeskiedenis en Nuwe Testament in 'n vereenvoudigde styl.

Sy publikasies en artikels oor die Afrikaanse Psalmberyming, oor die prediking en veral oor die doopsformulier, is 'n bewys van sy wye belangstelling en liefde vir besonderlik die gereformeerde leer, en is 'n mooi bydrae op die terrein van die liturgie en homiletiek.

Sy studente en veral die groot aantal nagraadse meesters- en doktorsgraad studente wat onder sy leiding studeer het, het steeds die hoogste agting en 
waardering vir sy leiding, sy besondere inspirasie en kundigheid waarmee hy hulle begelei het.

\section{Kerklike terrein}

Op kerklike terrein was V.E. d'Assonville besonder aktief. Weereens moet met enkele grepe volstaan word, en aksentueer ek slegs enkele besondere feite

Hy is dikwels na Sinodes van Kerke met wie die Gereformeerde Kerke in SuidAfrika korrespondensie het, en na Ekumeniese Sinodes afgevaardig. Op hierdie wyse het hy onder meer die kerke in Noord-Amerika, Skotland, Australië en Nederland besoek en bande verstewig. Die waardevolle bydrae wat hy in hierdie verband gelewer het, word weerspieel in die betrokke rapporte wat voor ons Nasionale Sinodes gedien het. Hierbenewens dien hy gedurende die verloop van jare op ' $\mathrm{n}$ groot aantal deputategroepe van Nasionale Sinodes.

Die kerke onthou hom as iemand wat dikwels ten tye van feeste of geleenthede kostelike redes gevoer het en adviese gegee het. Sy publikasie, getitel Kerk op die wit hooglande, waarin hy die geskiedenis van die kerke in Kenia beskryf, verhaal op 'n besondere manier die geskiedenis van die pioniers in 'n ver wêreld!

Eweneens bewys hy met sy preekbundels, waarvan daar reeds drie verskyn het, 'n groot diens aan die kerke. Die Woord van God word daarin op treffende wyse ontsluit.

In latere jare vanaf 1988 is hy vir meer as drie jaar met entoesiasme die redakteur van Die Kerkblad - 'n moeilike maar belangrike werk wat hy by sy werk as professor verrig.

Gedurende sy dienstyd aan die Teologiese Skool word hy in 1985 deur die Kuratorium vir 'n termyn as rektor benoem, en die leiding wat hy geneem het asook die inisiatiewe wat hy aan die dag gelè het, is besonderlik waardeer.

\section{Algemeen}

Die gemeenskap van Potchefstroom waar hy reeds lank woonagtig is en vir jare bedienaar van die Woord asook professor was, eer hom ook vir sy betrokkenheid en bydrae op die terrein van die onderwys en die kultuur

Die PU vir $\mathrm{CHO}$ het besondere waardering vir sy werk as akademikus, as lid van die Senaat en sy ternyn as Departementshoof van die Departement Bybelkunde.

Dit was vir ons almal 'n hartseersaak dat sy diens by die Teologiese Skool op 'n dissiplinêre wyse in Junie 1992 beëindig moes word, enkele maande voordat hy sou emeriteer. 
Ons betnerk egter duidelik die genadige en vergewende hand van die Here oor hom, en respekteer hom, sy vrou Therése en sy gesin vir die wyse waarop hulle die beproewing dra.

In Therése het die Here aan hom 'n besonder liefdevolle, begaafde en begenadigde vrou gegee, iemand wat hom onvoorwaardelik bystaan en onderskraag. Hulle kinders bly ook vir hulle 'n bron van vreugde.

Victor d'Assonville se liefde vir die Gereformeerde Kerke in Suid-Afrika wat hy as historikus so goed ken, sy besondere liefde en verdediging van die gereformeerde leer en sy volgehoue diens en bydrae in die belang van kerk en samelewing word opreg waardeer.

Ons dra hom en sy gesin aan die troon van God se genade en seën op en verseker hom van ons besondere waardering en agting vir sy lewe en werk. 
